\title{
EFFECT OF SN (TIN) ALLOYING ON NI-ZN FERRITES CHARACTERISTICS
}

\author{
Arif Mahmud ${ }^{1}$, Sharmim Islam ${ }^{2}$ and Syeda Sabikun Nahar ${ }^{1}$ \\ ${ }^{1}$ Lecturer, BGMEA University of Fashion \& Technology, Dhaka, Bangladesh. \\ ${ }^{2}$ Research Fellow, Jahangirnagar University, Savar, Bangladesh.
}

\begin{abstract}
Polycrystalline samples of $\mathrm{Ni}_{0.6-x / 2} \mathrm{Zn}_{0.4-x / 2} \mathrm{Sn}_{x} \mathrm{Fe}_{2} \mathrm{O}_{4}$ with $x=0,0.05,0.1,0.15$ and 0.2 were prepared by solid state reaction method and sintered at temperature $1325^{\circ} \mathrm{C}$ for hundred eighty minutes. The structural, magnetic and transport properties of various ferrite samples were studied with the Sn substitution. There were no traces of impurity of single phase cubic spinel, when ferrite samples were synthesized through $X$ ray diffractometer. Lattice parameters of the samples were found to decrease with the increase of Sn concentration in the system obeying Vegard's law. Magnetic properties (permeability) were analyzed considering the high frequency and temperature for different ferrites samples. The complex permeability measurements were calculated at room temperature using the LCR bridge. The frequency dependence of real permeability values were steady for $x=0,0.05,0.15$ and 0.20. Maximum values of permeability were observed at room temperature is 227 for the composition with $x=0.1$. Temperature dependent permeability is measured from room temperature to higher temperature region. Curie temperatures of all the samples were determined from the temperature dependence of initial permeability. It was observed to increase the Curie temperature with the increase of Sn concentration. Dielectric constant is dependent on frequency and decreased with the increase of frequency. The change of dielectric constant is higher at lower frequencies and very slow at higher frequencies. This is a usual dielectric behavior in most of the ferromagnetic materials, which follow Maxwell and Wagner prediction.
\end{abstract}

\section{Keywords}

Sintered, Ferrite, Magnetic Properties, X-ray Diffraction, Microstructure, Temperature, Frequency and Permeability.

\section{Introduction}

The spinel crystal structure of Ni-Zn ferrites are widely used in several electronic devices due to noticeable high electrical resistivity, low magnetic coercivity, mechanical hardness, chemical stability and reasonable cost. According to their structure spinel-type ferrites are natural super lattice. The composition and cation distribution of $\mathrm{Ni}-\mathrm{Zn}$ ferrites exhibits various magnetic properties. Theoretical application and experimental investigation field being enlarged by the use of remarkable behavior of magnetic and electric properties [1-3]. In case of application of high frequencies, magnetic materials such as iron and soft magnetic become useless because of their low electrical resistivity.

to flow within it, thereby it produces heat. This wasted energy or the produced heat often causes a serious problem. The frequency becomes higher and energy wastes more, as a result non-ferrite materials become inefficient. A significant number of applications of spinel oxides are useful for the high frequency devices $[4,5]$. Suitable temperature and time stability are important as 
International Journal of Advances in Materials Science and Engineering (IJAMSE) Vol.5, No.1, January 2016 additional characteristics to expand the use of ferrites into high frequency and wide-band transformers.

Spinel ferrite circulates a vital role in various technical fields such as telecommunication, AC and DC motors, switched mode power supplies, power distribution transformers, communication systems, digital memories, multilayer chip inductors, read/write heads for high-speed digital tape or disc readings, radar and satellite communications and in many other technological applications like photoelectrical devices, particle accelerators and gas sensors, magneto-mechanical stress and torque sensors, microwave devices and biomedical applications $[6,7]$.

In the ferrite system, dielectric properties provides some effective information on the behavior of electric charge carriers for better understanding of the mechanism of dielectric polarization. Generally, the dielectric constant decreases with the increase of frequency in ferrites. At the low frequency region, it decreases rapidly. On the other hand, at the high frequency region, it becomes slower. However, dielectric constant was found to be increased with the increase of temperature by Ahmed and Wasfy [8].

In particular, efficient high resistivity characteristic of ferrites are convenient for high frequency. The high frequency response of the complex permeability is therefore very useful in determining the convenient frequency range in which a particular ferrite material can be used. The relative magnitudes of the real and imaginary parts of the complex permeability provides the understanding of the mechanism of eddy current losses and damping of domain wall motion. The effect of composition and microstructure on the frequency response is therefore very useful. It has been reported that by incorporating small amount of tetravalent tin additive, the electrical and micro structural properties of $\mathrm{Ni}-\mathrm{Zn}$ ferrites are significantly influenced [9-10]. The main motive of this present research work was to prepare various samples of ferrites inducing $\mathrm{Sn}$ i.e. $\mathrm{Ni}_{0.6-}$ ${ }_{x / 2} \mathrm{Zn}_{0.4-x / 2} \mathrm{Sn}_{\mathrm{x}} \mathrm{Fe}_{2} \mathrm{O}_{4}(\mathrm{x}=0,0.05,0.1,0.15$ and 0.2$)$ to analyze the structural, magnetic and transport properties of various ferrite samples by solid state reaction method. Our research was also focused on to determine the transition temperature $\left(\mathrm{T}_{\mathrm{c}}\right)$ of Ferrimagnetic to Paramagnetic from the measurement of temperature dependent initial permeability and to evaluate the initial permeability as a function of frequency $(1 \mathrm{kHz}-13 \mathrm{MH})$.

\section{Materials and Methods}

Polycrystalline samples of $\mathrm{Ni}_{0.6-\mathrm{x} / 2} \mathrm{Zn}_{0.4-\mathrm{x} / 2} \mathrm{Sn}_{\mathrm{x}} \mathrm{Fe}_{2} \mathrm{O}_{4}$ were prepared using Conventional Ceramic Process or solid state reaction method and sintered at temperature $1325^{\circ} \mathrm{C}$ for three hours. The structural, magnetic and transport properties of various ferrites were investigated with the $\mathrm{Sn}$ substitution.

The raw materials for the preparation of $\mathrm{Ni}-\mathrm{Zn}$ ferrites were oxides of iron, Nickel and Zinc. The constituent in required stoichiometric proportions were weighed first and then thoroughly mixed using ceramic mortar and pestle by crushing, grinding and milling. The resultant powder was then ball milled 3 hours in distilled water or acetone/ Ethanol to produce a homogeneous mixture of the constituents. Then the mixtures are calcined in air or oxygen at a temperature above $1000^{\circ} \mathrm{C}$. This process is continued to form correct crystalline phase and then crushed again for fine powders. The pellets or toroid shaped samples are prepared from these calcined powders using die-punch assembly or hydrostatic or isostatic pressure. Sintering is carried out in the solid state, at temperature ranging $1100-1400^{\circ} \mathrm{C}$, for times of typically $1-40 \mathrm{~h}$ 
International Journal of Advances in Materials Science and Engineering (IJAMSE) Vol.5, No.1, January 2016 and in various atmospheres (e.g. Air, $\mathrm{O}_{2}$ and $\mathrm{N}_{2}$ ) [11-13]. Therefore prepared slurry were dried, palletized and then transferred to a porcelain crucible for pre-firing at temperature $950^{\circ} \mathrm{C}$ and was performed in Gallen Camp furnace available at the Materials Science Division, Atomic Energy Center, Dhaka, Bangladesh. $\mathrm{Ni}_{0.6-\mathrm{x} / 2} \mathrm{Zn}_{0.4-\mathrm{x} / 2} \mathrm{Sn}_{\mathrm{x}} \mathrm{Fe}_{2} \mathrm{O}_{4}$ formula has been utilized for the preparation of samples, by changing the concentration of $\mathrm{x}(\mathrm{x}=0.0,0.05,0.1,0.15$, and 0.2 ). The properties of $\mathrm{Ni}-\mathrm{Zn}$ samples are influenced considerably by sintering temperature and compositions.

$\mathrm{X}$-ray diffraction was carried out with an $\mathrm{X}$-ray diffractometer for the samples $\mathrm{Ni}_{0.6-\mathrm{x} / 2} \mathrm{Zn}_{0.4-}$ ${ }_{\mathrm{x} / 2} \mathrm{Sn}_{\mathrm{x}} \mathrm{Fe}_{2} \mathrm{O}_{4}(\mathrm{x}=0,0.05,0.1,0.15$ and 0.2$)$. For this purpose monochromatic $\mathrm{Cu}-\mathrm{K}_{\alpha}$ radiation was used. Micro structural study of the Ni-Zn ferrite samples was performed in order to have an insight of the grain structures. The samples of different compositions and sintered at different temperatures were chosen for this purpose. The samples were visualized under a highresolution optical microscope and then photographed. Linear intercept technique was used to measure the average grain sizes of all samples from optical micrographs [14]. Agilent Impedance Analyzer (model no. 4192A) was used to determine initial permeability spectra of Ni-Zn ferrite samples. Complex permeability of toroid shaped specimens was measured for all samples of Sn. Resistivity of the samples has been measured using conventional two probe method, using pellet samples of $7.24 \mathrm{~mm}-7.61 \mathrm{~mm}$ diameter and $1.12 \mathrm{~mm}-1.41 \mathrm{~mm}$ thickness. Dielectric Constants were measured using Hewlett Packart impedance analyzer as a function of frequency at room temperature.

\section{Result and Discussion}

\subsection{X-ray Diffraction}

$\mathrm{X}$-ray diffraction is useful technique to evaluate various phases of the synthesized ferrites as well as their unit cells parameters. In the present study X-ray diffraction technique has been utilized to discern these parameters. Figure 3.1 represents the fundamental reflections from the planes of (111), (220), (311), (222), (400), (422), (511) and (440) characterizing the cubic spinel structures for $\mathrm{x}=0,0.05,0.1,0.15,0.2$. This represents that synthesized ferrite compositions are of single phase cubic spinel. Investigated samples demonstrate the homogeneity. Analyzing the XRD patterns, we find that the intensity is maximum for plane (311) at the position 35.5 of miller indices. XRD patterns were investigated and came to know the position of the peaks comply the mentioned values [15].

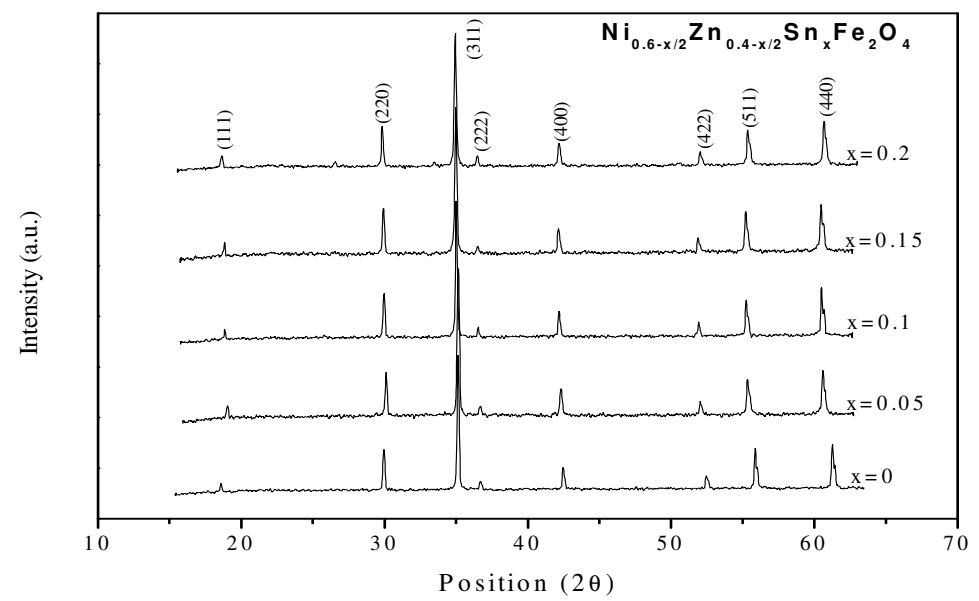

Figure 3.1: X-ray diffraction patterns for $\mathrm{Ni}_{0.6-\mathrm{x} / 2} \mathrm{Zn}_{0.4-\mathrm{x} / 2} \mathrm{Sn}_{\mathrm{x}} \mathrm{Fe}_{2} \mathrm{O}_{4}$ with $\mathrm{x}=0$, 0.05, 0.1, 0.15, 0.2. 
For $\mathrm{x}=0.2$, the $\mathrm{Sn}$ ion exhibits strange behaviour. This strange behaviour indicates the solubility limit of $\mathrm{Sn}^{4+}$ ions in the spinel lattice [16]. In Table 3.1, the positions of the peaks and their corresponding miller indices for the studied samples have been investigated.

Table 3.1: X-ray peak positions for $\mathrm{Ni}_{0.6-\mathrm{x} / 2} \mathrm{Zn}_{0.4-\mathrm{x} / 2} \mathrm{Sn}_{\mathrm{x}} \mathrm{Fe}_{2} \mathrm{O}_{4}$ samples.

\begin{tabular}{|c|c|c|c|c|c|c|c|c|}
\hline \multirow[b]{2}{*}{ Composition } & \multicolumn{8}{|c|}{ X-ray peak position with Miller indices $2 \theta$ (degree) } \\
\hline & $(111)$ & (220) & $(311)$ & (222) & $(400)$ & $(422)$ & (333) & (440) \\
\hline $\mathrm{Ni}_{0.6} \mathrm{Zn}_{0.4} \mathrm{Fe}_{2} \mathrm{O}_{4}$ & 18.37 & 30.19 & 35.5 & 37.17 & 43.19 & 53.57 & 57.11 & 62.71 \\
\hline $\begin{array}{l}\mathrm{Ni}_{0.575} \mathrm{Zn}_{0.375} \mathrm{Sn} \\
0_{0.05} \mathrm{Fe}_{2} \mathrm{O}_{4}\end{array}$ & 18.33 & 30.15 & 35.51 & 37.19 & 43.17 & 53.51 & 5705 & 62.65 \\
\hline $\begin{array}{l}\mathrm{Ni}_{0.55} \mathrm{Zn}_{0.35} \mathrm{Sn} \\
0.1 \mathrm{Fe}_{2} \mathrm{O}_{4}\end{array}$ & 18.33 & 30.17 & 35.53 & 37.17 & 43.17 & 53.55 & 57.09 & 62.71 \\
\hline $\begin{array}{l}\mathrm{Ni}_{0.525} \mathrm{Zn}_{0.325} \mathrm{Sn} \\
0_{0.15} \mathrm{Fe}_{2} \mathrm{O}_{4}\end{array}$ & 18.33 & 30.15 & 35.51 & 37.13 & 43.17 & 53.53 & 57.05 & 62.67 \\
\hline $\begin{array}{l}\mathrm{Ni}_{0.5} \mathrm{Zn}_{0.3} \mathrm{Sn}_{0.2} \\
\mathrm{Fe}_{2} \mathrm{O}_{4}\end{array}$ & 18.29 & 30.69 & 35.45 & 37.65 & 43.09 & 53.43 & 56.95 & 62.53 \\
\hline
\end{tabular}

Figure 3.2 shows the variation of lattice constant with increase in Sn concentration (x). From the figure we find that with the increase of Sn concentration (x), lattice parameters are increasing linearly [17], which shows that the variation of tetrahedral radius with increasing Sn concentration.

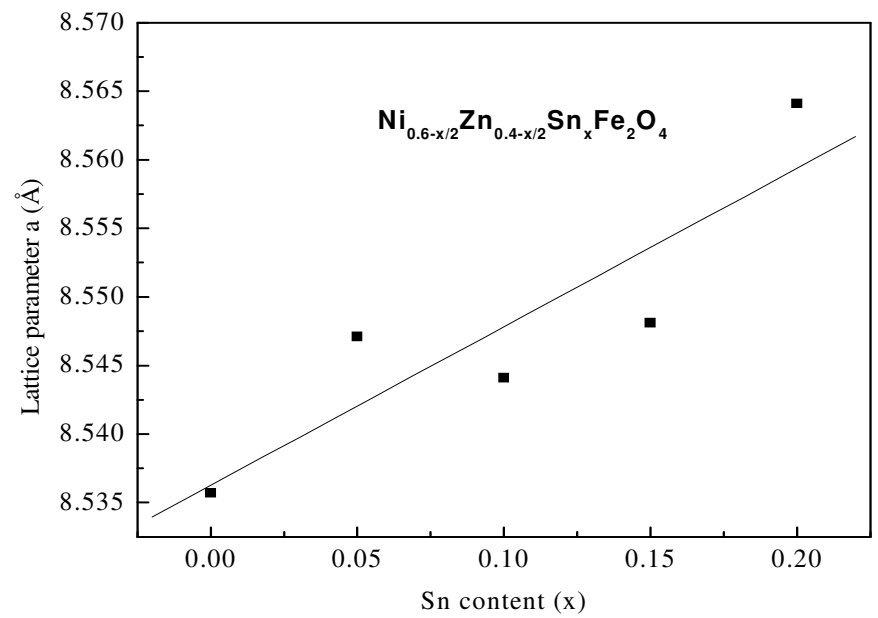

Figure 3.2: Lattice parameters as a function of $\mathrm{Sn}$ content $\left(\mathrm{Ni}_{0.6-\mathrm{x} / 2} \mathrm{Zn}_{0.4-\mathrm{x} / 2} \mathrm{Sn}_{\mathrm{x}} \mathrm{Fe}_{2} \mathrm{O}_{4}\right)$.

The lattice parameter obtained from different composition of $\mathrm{Ni}, \mathrm{Zn}, \mathrm{Sn}$ is shown Figure 3.2.

The physical, electrical and magnetic properties of ferrites were analyzed from the distribution of cations in the octahedral B-sites and tetrahedral A-sites. There exists a correlation between the ionic radius and the lattice constant, the increase of the lattice constant is proportional to the 
International Journal of Advances in Materials Science and Engineering (IJAMSE) Vol.5, No.1, January 2016 increase of the ionic radius. The lattice parameter was reported to follow the Vegard's law rule of linearity [18].

The magnetic and electric properties are dependent on the density of ferrites sample. High permeability of any ferrites could be attained by raising the concentration. The theoretical density calculated from the determined lattice parameter and the bulk density measured from the ratio of mass volume of all the studied samples.

Table 3.2: The lattice parameter, theoretical and bulk density and porosity of the $\mathrm{Ni}_{0.6-\mathrm{x} / 2} \mathrm{Zn}_{0.4-\mathrm{x} / 2} \mathrm{Sn}_{\mathrm{x}} \mathrm{Fe}_{2} \mathrm{O}_{4}$ samples.

\begin{tabular}{|l|c|c|c|c|}
\hline Sample Composition & $\mathrm{a}(\AA)$ & $\begin{array}{c}\rho_{\text {th }} \\
\left(\mathrm{gm} / \mathrm{cm}^{3}\right)\end{array}$ & $\begin{array}{c}\rho_{\mathrm{B}} \\
\left(\mathrm{gm} / \mathrm{cm}^{3}\right)\end{array}$ & $\begin{array}{l}\text { Porosity } \\
(\%)\end{array}$ \\
\hline $\mathrm{Ni}_{0.6} \mathrm{Zn}_{0.4} \mathrm{Fe}_{2} \mathrm{O}_{4}$ & 8.535791 & 5.06 & 4.23 & 16.4 \\
\hline $\mathrm{Ni}_{0.575} \mathrm{Zn}_{0.375} \mathrm{Sn}_{0.05} \mathrm{Fe}_{2} \mathrm{O}_{4}$ & 8.54717 & 4.98 & 4.32 & 13.2 \\
\hline $\mathrm{Ni}_{0.55} \mathrm{Zn}_{0.35} \mathrm{Sn}_{0.1} \mathrm{Fe}_{2} \mathrm{O}_{4}$ & 8.544105 & 5.27 & 4.78 & 9.2 \\
\hline $\mathrm{Ni}_{0.525} \mathrm{Zn}_{0.325} \mathrm{Sn}_{0.15} \mathrm{Fe}_{2} \mathrm{O}_{4}$ & 8.548157 & 5.82 & 5.37 & 7.7 \\
\hline $\mathrm{Ni}_{0.5} \mathrm{Zn}_{0.3} \mathrm{Sn}_{0.2} \mathrm{Fe}_{2} \mathrm{O}_{4}$ & 8.564141 & 5.55 & 5.14 & 7.3 \\
\hline
\end{tabular}

Table 3.2 shows the lattice parameter, bulk and theoretical density and porosity as a function of concentration of $x$ for all the compositions. Figure 3.3 (a) and 3.3 (b) shows the density and porosity as a function of $\mathrm{x}$ for all the composition respectively. From all sample composition it was found that theoretical density higher than the bulk density. The X-ray and bulk density increase with increasing Sn content due to the higher atomic weight and density of Sn.
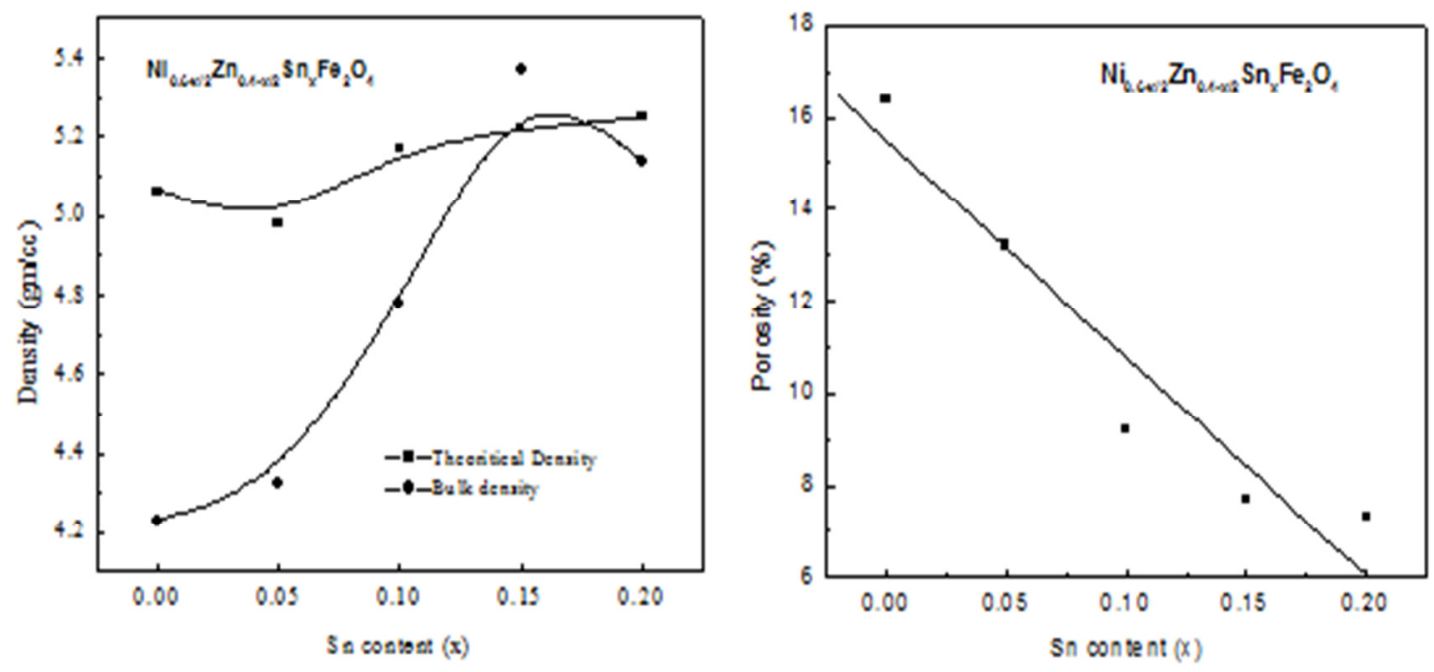

Figure 3.3 (a): Variation of density with increase of Sn content.

Figure 3.3 (b): Variation of porosity with the increase of $\mathrm{Sn}$ content. 


\subsection{Microstructures}

The optical micrographs of $\mathrm{Ni}_{0.6-\mathrm{x} / 2} \mathrm{Zn}_{0.4-\mathrm{x} / 2} \mathrm{Sn}_{\mathrm{x}} \mathrm{Fe}_{2} \mathrm{O}_{4}$ samples sintered at $1325^{\circ} \mathrm{C}$ are shown in Figure 3.4. The results show that an increase in $\mathrm{Sn}$ content increases the grain size and decreases the porosity. All the samples sintered bellow than $1325^{\circ} \mathrm{C}$ (not shown) with very small grains and open porosity free of intragranular pores.
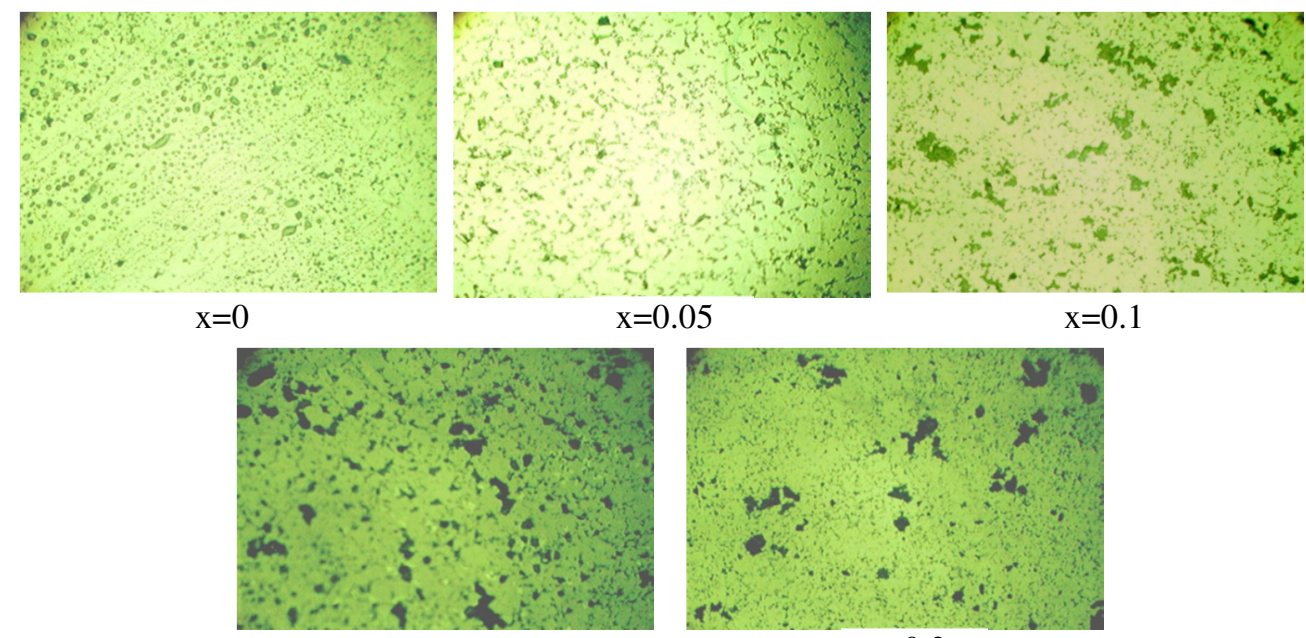

$\mathrm{x}=0.05$

$$
\mathrm{x}=0.1
$$

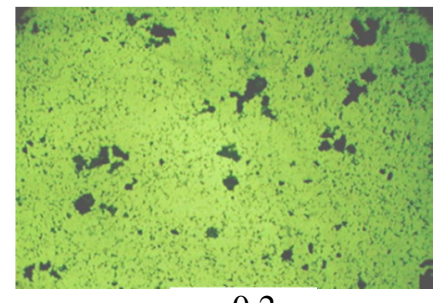

Figure 3.4: The optical micrographs of $\mathrm{Ni}_{0.6-\mathrm{x} / 2} \mathrm{Zn}_{0.4-\mathrm{x} / 2} \mathrm{Sn}_{\mathrm{x}} \mathrm{Fe}_{2} \mathrm{O}_{4}$ samples.

This low sintering temperature was deficient for the perfect formation of microstructure. But this sintering temperature was suffices to produce a homogeneous microstructure with grain size and a uniform size distribution. We observed that there was no noticeable variation of lattice parameter with grain size. Even porosity may be strongly related to boundaries since they can remove porosity.

\subsection{Permeability Measurement}

The complex permeability of spinel oxides is an important parameter in respect of its frequency dependence and its dependence on composition. The $\mathrm{AC}$ magnetic properties of the system $\mathrm{Ni}_{0.6-}$ ${ }_{\mathrm{x} / 2} \mathrm{Zn}_{0.4-\mathrm{x} / 2} \mathrm{Sn}_{\mathrm{x}} \mathrm{Fe}_{2} \mathrm{O}_{4}$ have been determined using an impedance analyzer in the LCR Bridge technique. Ring shaped specimens has been used to measure the complex permeability at room temperature. The real part of the complex permeability of the samples determined by LCR Bridge in the frequency range ${ }_{2} \mathrm{~K}_{5} \mathrm{KHz}$ to $13 \mathrm{MHz}$ is presented in Figure 3.5.

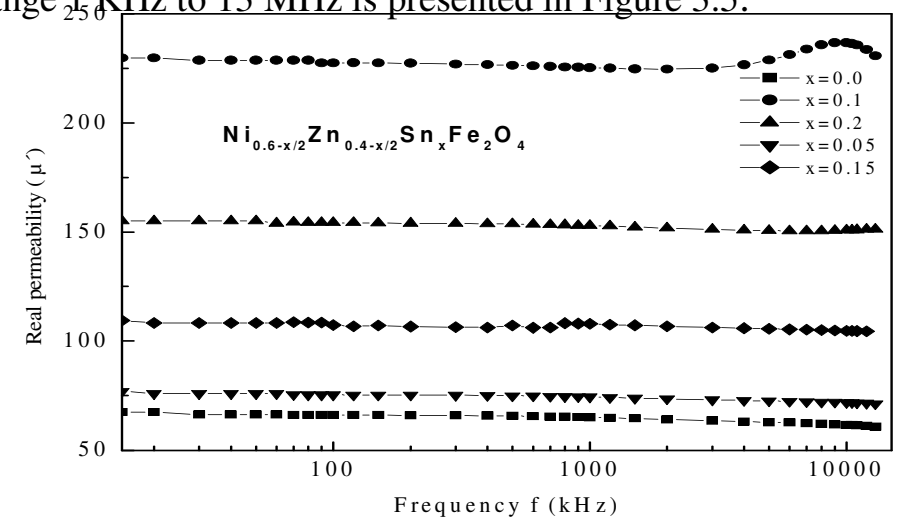

Figure 3.5: Real permeability as a function of frequency. 
The permeability becomes steady for the samples $x=0,0.05,0.15$ and 0.2 . The values of the real part of the permeability in this range are quite small, being around 50-150 and is increasing with the Sn content. The highest value of permeability is 227 for $\mathrm{x}=0.1$.

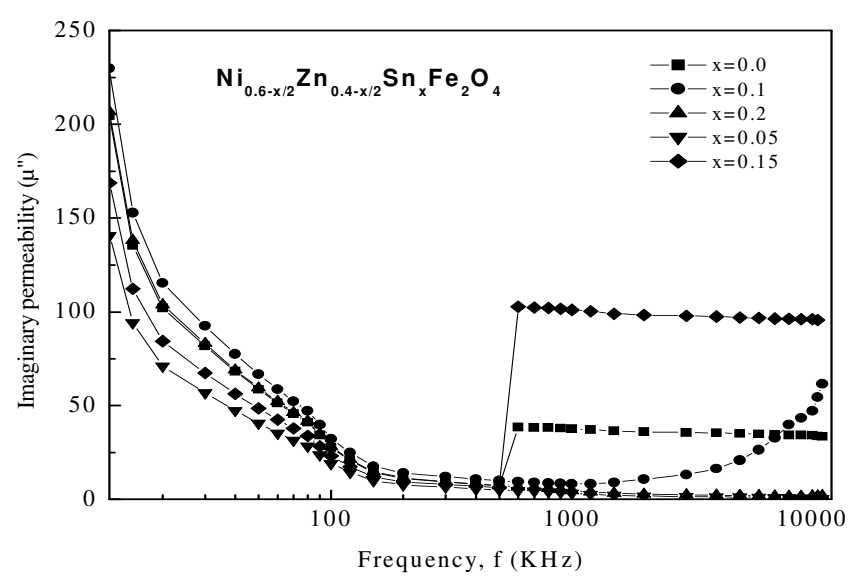

Figure 3.6: Imaginary permeability as a function of frequency.

The imaginary part of the complex permeability of the samples $\mathrm{Ni}{ }_{0.6-\mathrm{x} / 2} \mathrm{Zn}{ }_{0.4-\mathrm{x} / 2} \mathrm{Sn}_{\mathrm{x}} \mathrm{Fe}_{2} \mathrm{O}_{4}$, as determined by LCR Bridge in the frequency range $1 \mathrm{KHz}$ to $13 \mathrm{MHz}$, are presented in Figure 3.6. For $\mathrm{x}=0.1$ samples the permeability values becomes maximum the initial permeability increases with increasing Sn content which is consistent with the increase in density with Sn content. The permeability of magnetic ferrites is dependent on the concentration with Sn contents. Increasing density of ferrites responsible for reducing the demagnetization field but also raise the spin rotational contribution, which in turn increases the permeability [19].

\subsection{Frequency Dependence of Dielectric Constant}

The variation of dielectric constant with frequency represented in Figure 3.7 within the frequency range of $1 \mathrm{KHz}$ to $13 \mathrm{MHz}$ at room temperature. Dielectric constant is dependent on frequency and decreased with the increase of frequency. The change of dielectric constant is higher at lower frequencies and very slow at higher frequencies. This is usual dielectric behavior exhibits in almost all ferromagnetic materials, because of interfacial polarization [20]. All the samples have high value of dielectric constant in the order of $10^{3}-10^{5}$ at low frequencies. This remarkable value at lower frequency region is due to the Maxwell-Wagner interfacial type of polarization for the inhomogeneous double layer dielectric structure which is in agreement with Koops Phenomenological theory [21]. 


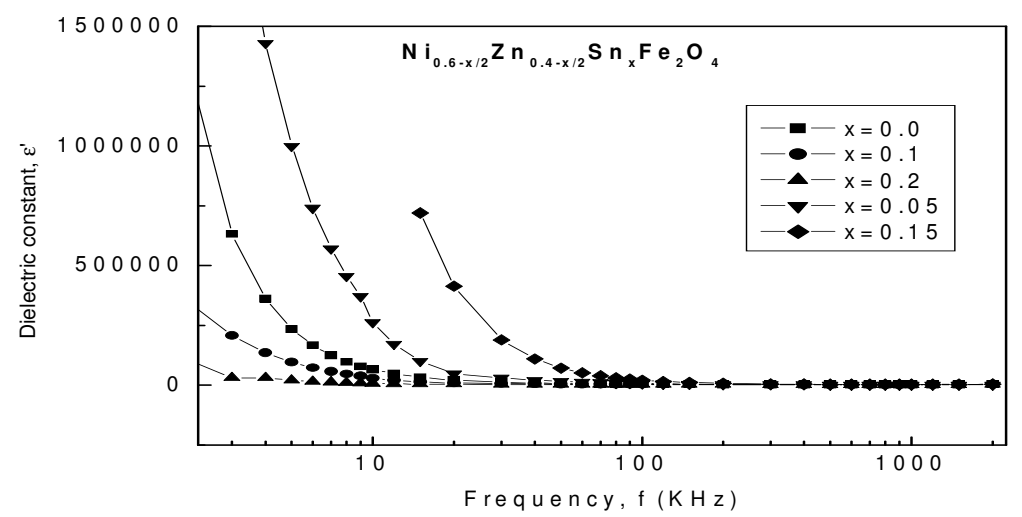

Figure 3.7: Changes of dielectric constant with frequency for all the samples.

\subsection{Resistivity}

Resistivity is an important electrical property of ferrite materials. The method of sample preparation, chemical composition, grain size and sintering temperature has vital role in electrical properties of ferrite materials. The temperature dependence of electrical resistivity of $\mathrm{Ni}_{0.6-\mathrm{x} / 2} \mathrm{Zn}_{0.4-}$ ${ }_{x / 2} \mathrm{Sn}_{\mathrm{x}} \mathrm{F}_{2} \mathrm{O}_{4}$ ferrites of different compositions has been investigated. Figure 3.8 illustrate the fluctuation of resistivity with raising temperature. From figure one can observe that in the investigated temperature range, the resistivity decreased by about three orders of magnitude with increased temperature i.e. conductivity increases with higher values of temperature. The mobility of charge carriers is responsible for the conductivity of these samples.

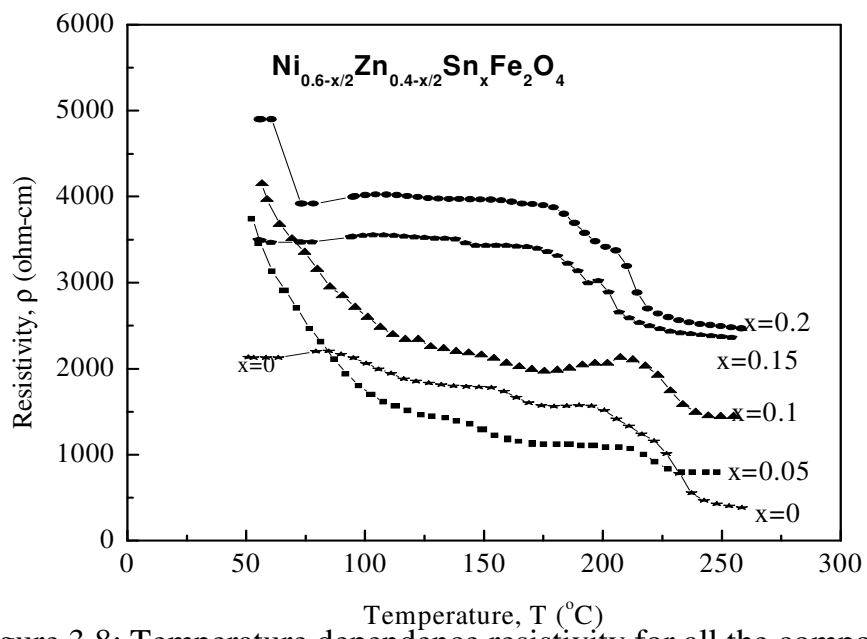

Figure 3.8: Temperature dependence resistivity for all the composition.

The activation energy of any ferrites samples is dependent on Sn concentration and increases with higher $\mathrm{Sn}$ content concentration. It is observed that the high activation energy goes hand in hand with low conductivity of the ferrite. So activation energies are inversely proportional to the electrical conductivity. 
International Journal of Advances in Materials Science and Engineering (IJAMSE) Vol.5, No.1, January 2016

\section{Conclusions}

To observe the effect of the substitution of $\mathrm{Sn}$ in structural, magnetic and transport properties single phase polycrystalline samples $\mathrm{Ni}_{0.6-\mathrm{x} / 2} \mathrm{Zn}_{0.4-\mathrm{x} / 2} \mathrm{Sn}_{\mathrm{x}} \mathrm{Fe}_{2} \mathrm{O}_{4}$ for different concentration of $\mathrm{x}$ were prepared by solid state reaction method. Microstructures are studied by optical micrographs.

There were no traces of impurity of single phase cubic spinel, when ferrite samples were synthesized through X-ray diffractometer. Lattice parameters of the samples were found to decrease with the increase of Sn concentration in the system. The ionic radii plays very important role in increase of lattice parameter with increasing Sn content in these samples. From the optical microscopy it is observed that less than $1325^{\circ} \mathrm{C}$ sintering temperature was insufficient for the complete formation of the microstructure.

The frequency dependence of real permeability shows no change for the samples $\mathrm{x}=0,0.05,0.15$ and 0.2 . For $\mathrm{x}=0.1$ sample the real permeability value becomes maximum. The frequency response of the complex permeability is determined by the natural frequency of the magnetic domains of the samples, which in their turns are controlled by grain size, their moments and the elastic forces coupling the domains to the lattice. Curie temperatures of all the samples have been determined from the temperature dependence of initial permeability. It is observed that Curie temperature increases with the increase of Sn concentration.

This is the contribution of higher concentration of nonmagnetic and large ionic radius of Sn in the composition. Dielectric constant is dependent on frequency and decreased with the increase of frequency. The change of dielectric constant is higher at lower frequencies and very slow at higher frequencies. This is a usual dielectric behavior exhibit in most of the ferromagnetic materials.

It is observe that in the investigated temperature range, the resistivity decreased with the increase of Sn content. The mobility of charge carriers is responsible for strong conductivity of these ferrite samples.

\section{Compliance with Ethical Standards:}

\section{Funding:}

This research was carried out in the Materials Science Division of Atomic Energy Centre, Dhaka, Bangladesh as a part of fulfillment of the degree of Masters of Science in Physics at Jahangirnagar University, Bangladesh. There were no fund/grants for this research work.

\section{Conflict of Interest:}

We the authors of this manuscript declare that we had no conflict of interest. 
International Journal of Advances in Materials Science and Engineering (IJAMSE) Vol.5, No.1, January 2016

\section{References}

[1] S. T. Mahmud, A. K. M. Akther Hossain, A. K. M. Abdul Hakim, M. Seki, T. Kawai and H. Tabata, "Influence of microstructure on the complex permeability of spinel type Ni-Zn ferrite", Journal of Magnetism and Magnetic Materials, 305, 269 (2006).

[2] M. El-Shabasy, "DC electrical properties of Ni-Zn ferrites", Journal of Magnetism and Magnetic Materials, 172, 188 (1997).

[3] M. I. Rosales, E. Amano, M. P. Cuautle and R. Valenzuela, "Impedance spectroscopy studies of NiZn ferrites", Materials Science and Engineering, B49, 221 (1997).

[4] M. S. Ruiz, P. G. Bercoff and S. E. Jacobo, "Sheilding Properties of CuNiZn Ferrite in the Radio Frequency Range", Ceramics International, $39 \quad$ (5), 4777- $4782 \quad$ (2013). http://dx.doi.org/10.1016/j.ceramint.2012.11.067

[5] M. Khalaj-Amirhosseini, "Microwave Filters Using Waveguides Filled by Multilayer Dielectric", $\begin{array}{lllll}\text { Progress in Electromagnetics } & \text { Research, }\end{array}$ http://dx.doi.org/10.2528/PIER06102502

[6] M. Pasquale, C. P. Sasso, M. Velluto, and S. H. Lim, "Stress Sensing with Co based Ferrite Composites", Journal of Magnetism and Magnetic Materials, 242, 1460-1463 (2002). http://dx.doi.org/10.1016/S0304-8853(01)01103-9

[7] M. M. Yallapu, S. F. Othman, E. T. Curtis, B. K. Gupta, M. Jaggi, and S. C. Chauhan, "Multifunctional Magnetic Nanoparticles for Magnetic Resonance Imaging and Cancer Therapy", Biomaterials, 32, 1890-1905 (2011). http://dx.doi.org/10.1016/j.biomaterials.2010.11.028

[8] M. A. Ahmed, and M. H. Wasfy, "Effect of charge transfer behaviour on the dielectric and ac conductivity of Co-Zn ferrite doped with rare earth element", Ind. J. Pure and Appl. Phys., 41, 731738 (2003).

[9] U. Varshney. R. K. Puri, R. G. Rao. and R. G. Mendiratta, "Anomalous electrical behavior of nickelzinc ferrites doped with tetravalent-tin impurity" In ferrites. Proc. IFC 3 (Sept-Oct.1980. Japan), 207 (1981).

[10] U. Varshney. "Microstructural, electrical, magnetic and Mossbauer investigations of tetravalent -tin Substituted nickel - zinc ferrites", thesis. IIT, New Delhi, India, 1982.

[11] B. D. Cullity, "Introduction to Magnetic Materials", Addison-Wiseley Publishing Company, Inc, California (1972).

[12] R. J. Brook, Sintering: An Overview, concise Encyclopedia of Advanced Ceramic Materials, Pergamon Press, Oxford, 438 (1991).

[13] P. Reijnen, Science of Ceramics, Academic Press, London, 3, 245-261 (1967).

[14] A. K. M. Akther Hossain, "Investigation of colossal magnetoresistance in bulk and thick film magnetites," Ph. D. Thesis, Imperial College, London (1998).

[15] A Goldman, Handbook of Modern Ferromagnetic Materials, Kulwer Acad. Pub, Boston, U.S. (1999).

[16] J. E. Huheey, E. A. Keiter, R. J. Keiter, "Principles of structure and reactivity", Harper Collins, College Publishers, (1993).

[17] L. J. Berchmans, R. K. Selvan, P. N. S. Kumar, C. O. Augustin, "Structural and electrical properties of $\mathrm{Ni}_{1-\mathrm{x}} \mathrm{Mg}_{\mathrm{x}} \mathrm{Fe}_{2} \mathrm{O}_{4}$ synthesized by citrate gel process", Journal of Magnetism and Magnetic Materials, 279, 103-110 (2004).

[18] L. Vegard, "Die Konstitution der Mischkristalle und die Raumfüllung der Atome”, Zeits. Phys. 5, 1726 (1921).

[19] J. J. Shrotri , S. D. Kulkaai, C. E. Deshpande, S. K. Date, “ Effect of Cu substitution on the magnetic and celectrical properties of $\mathrm{Ni}-\mathrm{Zn}$ ferrite synthecised by soft chemical method" Matter. Chem. Phys, 59(1), 1-5 (1999).

[20] L. I. Rabinkin, Z. I. Novikova, "Ferrites", Doklady Akademii Nauk SSSR, Minsk, USSR, 146 (1960).

[21] C. G. Koops, "On the Dispersion of Resistivity and Dielectric Constant of Some Semiconductors at Audiofrequencies," Physical Review, 83(1), 121-124 (1951). http://dx.doi.org/10.1103/PhysRev.83.121 